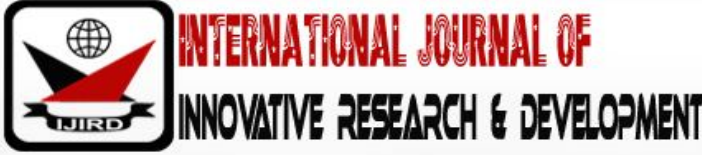

ISSN 2278 - 0211 (Online)

\section{Exploring the Multi-Dimensional Effect of Pre-Service Teachers Intrinsic Motivation on Mathematics Achievement}

\author{
\begin{tabular}{c} 
Mohammed Nurudeen Alhassan \\
Mathematics Tutor, Department of Mathematics \& ICT, OLA College of Education, Ghana \\
Jonathan A. Fletcher \\
Professor, School of Education and Leadership, University of Ghana, Ghana \\
\hline
\end{tabular}
}

Abstract:

The study explored the Multi-Dimensional Effect of Pre-Service Teachers' Intrinsic Motivation on Mathematics Achievement. In order to identify the predictor(s) among the dimensions of intrinsic motivation, to merit the attention of mathematics educators, The Intrinsic Motivation Instrument which comprises perceived Interest, perceived competence, perceived usefulness and perceived effort as potential predictors of Mathematics achievement was used. Based on this questionnaire a convenient sample of 89 pre-service teachers, made up of 77 male and 12 female were used. A multiple linear regression conducted, showed that only students' perceived interest is the only predictor of mathematics achievement. That means that students who demonstrate high levels of interest in the study of mathematics are more likely to succeed in it. It is important to employ all means possible to develop students' interest in mathematics as it appears to be the one of the driven force for students' mathematics achievement.

Keywords: Correlation, regression, interest in mathematics, motivation, factor analysis

\section{Introduction}

The study explored the Multi-Dimensionality of Pre-Service Teachers' Intrinsic Motivation on Mathematics Achievement. Spinath and Steinmayr (2007) declared that perhaps more than anything else, to be well equipped for life-long learning, individuals needed a high, sustained motivation to learn. This is an admission of how important motivation is to learning. Fresh students in Universities exhibit newfound freedom. It is at this time that the students' academic motivations largely dictated the choices that they made, and whether or not they met the different standards and expectations that is required of them (Clark \& Schroth 2010). Schick and Phillipson (2009) stated that there exists a consensus that motivation promotes academic performance in students. It seemed therefore, that motivation contributed to the variance in academic achievement.

Motivation refers to "a student's willingness, need, desire and compulsion to participate in, and be successful in the learning process" (Bomia, Beluzo, Demeester, Elander, Johnson, \& Sheldon, 1997, p.1). Middleton and Spanias (1999) viewed motivation as reasons individuals have for behaving in a given situation. Mwamwenda (1995) defines motivation as "an energiser or a driven force, a desire or an urge that causes an individual to engage in certain behaviours" (p. 259). Comprehensively defined by Ames (1992) as part of one's goal structures, one's beliefs about what is important and determines whether one will engage in a given pursuit. Motivation is the attribute that moves us to do or not to do something (Gredler, 2001). Skinner and Belmont (1991) explained that students who are motivated to engage in school "select tasks at the border of their competencies, initiate action when given the opportunity, and exert intense effort and concentration in the implementation of learning tasks; they show generally positive emotions during ongoing action, including enthusiasm, optimism, curiosity, and interest" (p. 3).

Motivation, described as a process through which individuals whip up and sustain interest in an activity. Other researchers viewed motivation as a process through which an individual's needs and desires are set in motion (Alexander \& Murphy, 1998; Pintrich, Marx \& Boyle, 1993). Academic motivation reflects students' levels of persistence, interest in the subject matter, and academic effort (DiPerna \& Elliot, 1999); it plays a major role in academic success (Alexander, 2006; Ames \& Ames, 1985; Dweck \& Legget, 1988; Wylie, 1989). While motivation is critically important to student learning (Pintrich \& Schunk, 2002), lack of motivation is a frequent problem with students at all levels. To be actively involved in an activity requires something to hook you onto it, motivation has that magnet that can attract and maintain the interest of an individual in the activity. This attraction can be internal or external, depending on the underlining factor(s). 
People take up things or do some things simply because it interests them or because they think it is good or enjoyable. Their concern is not about what they will get out of it, but because of sheer satisfaction and joy experienced in the activity. If learners are motivated to attain a given goal, this goal directed their activities in the direction of achieving the goal. They experienced pleasure in doing the activity. They tend to develop inner satisfaction, confidence and are successful. For instance, a person interested in dance, rehearses for hours not because she or he wants to win some competition, but just for the pure joy of dancing. A student could be studying hard not to get excellent grades, but because she or he is interested in the subject. In such a case, even if the student fails or gets less mark she or he continues to study that subject and takes failures as learning lessons. On the other hand, if a student had studied in order to gain recognition among her or his peers, then the underlining factor is an external force.

In this study, intrinsic motivation is used. Intrinsic motivation reflects the propensity and eagerness of a person to engage in activities that interest her or him. It is also defined as the performance of a task for the inherent satisfaction it brings to an individual rather than for some separate consequence (Ryan \& Deci, 2000). Nolen and Nicholls (1993) conceptually defined intrinsic motivation as the internal drive to engage or perform an activity. Intrinsic motivation is a process of arousal and satisfaction in which the rewards come from carrying out an activity rather than from the result of the activity. Development of academic intrinsic motivation in young children is an important goal for educators because of its inherent importance for future motivation, as well as for children's effective school functioning (Gottfried, 1990). This justifies the need to consider intrinsic motivation in this research among adult learners.

Intrinsic motivation in educational psychology literature is described in terms of three interconnected elements among students. These are special drive to tackle more challenging tasks; as learning, driven by curiosity or special interests; as a development of competence; and mastery of learning tasks in which learning is seen as valuable in itself (Eccles, Wig field, \& Schiefele, 1998; Pintrich \& Schunk, 1996; Stipek, 1998). Students who demonstrate signs of internal driver towards activities, show signs of competence and place more value on learning activities are more likely to be intrinsically motivated than students who do not show these signs.

\section{Material and Methods}

The Correlation study design was used for this research. This design is best suited for studies aimed at finding a number of variables and their relationships (Cohen, Manion \& Morrison, 2000). Correlation studies are mainly concerned with achieving a fuller understanding of the complexity of phenomena or, by studying the relationships between the variables hypothesized as being related (Cohen, Manion \& Morrison, 2000). The target population was all first year Bachelor of Education (Mathematics) students. The sampling design used was non-probability convenience sampling. Students who were available and consented to participate in the work were used. In all 96 students were sampled, but only 89 submitted their completed questionnaires.

The instruments for the study were a questionnaire referred to as Intrinsic-Motivation ( IMOT) on a 5-point likert scale ranging from strongly agree (coded 5) to strongly disagree (coded 1) and End of First Semester Examination in Algebra and Trigonometry. The IMOT was a multi-dimensinal instrument with perceived Interest, perceived competence, perceived anxiety, and perceived usefulness and perceived, adapted from the Intrinsic Motivation Inventory (IMI) of Mc Auley, Duncan, and Tammen (1987). The authors administered the questionnaire to 96 respondents who were to indicate the extent to which they disagreed or agreed with the statements on a 5 -point Likert-type scale lasting between 5 to 10 minutes, after which the questionnaire was collected. The questionnaires were serially numbered. This is required in order to match the mathematics achievement scores to the appropriate student. The respondents were assured that their identities and the results would be treated with confidentiality. The total number completed and returned questionnaires was 89. In addition, two letters were presented to the Head of Students' Records and Management Information Section (SRMIS) requesting for Algebra and Trigonometry first semester results of Level 100 B. Ed (Mathematics).

\subsection{Theory}

Some researchers have used motivational approaches, such as expectancy-value theory (Berndt \& Miller, 1990), goal theory (Meece \& Holt, 1993), and self-efficacy theory (e.g., Zimmerman, Bandura, \& Martinez-Pons, 1992) to examine the relationship between academic motivation and academic achievement. Another perspective that appears promising and pertinent for the study of academic achievement is Deci and Ryan's (1985, 1991 \& 2000) motivational approach: the SelfDetermination Theory (SDT). This theoretical perspective has generated a considerable amount of research in the field of education (Deci, Valler and, Pelletier \& Ryan, 1991). For this reason, the SDT is adopted in this work. Ryan, Kuhl and Deci (as cited in Areepattamannil and Freeman, 2008), the self-determination theory is an approach to human motivation that highlights the importance of the psychological need for autonomy. Autonomy implies that individuals experience choice in the initiation, maintenance, and regulation of their behaviours (Deci \& Ryan, 1985, 2000). To choose to engage in an activity rather than being required to perform it in order to satisfy the expectations or demands of others, there is an implication that the person would rather be doing this activity, rather than other activities she or he could equally be doing at the time. 


\subsection{Calculation}

There are generally three types of internal consistency measures, namely the split-half-method, the KuderRichardson-method, and the Cronbach alpha method. This study however employed the Cronbach alpha method. The Cronbach alpha method assumes that all statements are equivalent in the determination of internal consistency of the questionnaire. It is a much more general form of internal consistency and is used for statements that are not scored right or wrong (McMillan and Schumacher 2006). In this study the statements in the IMOT questionnaire were not scored right or wrong. The Cronbach alpha is the most appropriate kind of reliability in the case of survey research, as well as for other questionnaires where there is a range of possible answers for each item (McMillan \& Schumacher 2006). As mentioned before, this study used the correlation study research design and there was a range of possible answers for each statement in the questionnaires. Therefore, the Cronbach alpha method was considered the most appropriate measure of reliability for this study.

The internal consistency of the items from the different sub-scales for the IMOT questionnaire was determined. This was determined by calculating the Cronbach alpha's $\alpha$-coefficients with the help of the SPSS version 16 computer software program. According to McMillan and Schumacher (2006) an acceptable range of reliability coefficients for most instruments is between .70 and .90 . The overall Cronbach alpha's $\alpha$-coefficient of the IMOT instrument was .73. This value is slightly above the minimum satisfactory level on the basis of Nunnally's (1978) and McMillan and Schumacher (2006) criterion.

\subsubsection{Construct Validity}

De Vos, Strydom, Fouche and Delport (2005) stated that, construct validity is difficult to validate, as it involves determining the degree to which an instrument successfully measured a theoretical construct. This difficulty arose because of the abstract nature of the theoretical constructs purported to be measured. Again, they stated that construct validity concentrated on the meaning of the instrument and the measuring (i.e. what, how and why it operates the way that it does).

\begin{tabular}{|l|c|c|}
\hline \multicolumn{2}{|c|}{ Kaiser-Meyer-Olkin Measure of Sampling Adequacy. } & $\mathbf{. 7 0 5}$ \\
\hline \multirow{2}{*}{ Bartlett's Test of Sphericity } & Approx. Chi-Square & 374.039 \\
\cline { 2 - 3 } & Df & 78 \\
\cline { 2 - 3 } & Sig. & .000 \\
\hline
\end{tabular}

Table 1: Kaiser-Meyer-Olkin and Bartlett's Test

Factor analysis was used to assess the construct validity of the IMOT instrument. Field (2005a, 2005b), Ahadzie (2007) and Owusu and Badu (2009), reported that factor analysis is useful for finding clusters of related variables and it is ideal for reducing a large number of variables into a more manageable form. There are two preconditions that sample should meet before conducting factor analysis: first the appropriate sample size and whether sample data is not an identity matrix. These two preconditions should be met to grantee the reliability of the factor analysis (Field, 2005a, 2005b).

The data was subjected to the Kaiser-Meyer-Olkin (KMO) measure of sampling adequacy, which recorded substantial value of .705. The KMO statistic varies between 0 and 1 with a value of 0 indicates that the sum of partial correlations is large relative to the sum of correlations, indicating diffusion of pattern of the correlations and hence factor analysis is likely to be inappropriate (Gorsuch, 1983; Field, 2005a). A value close to 1.00 indicates that patterns of correlation are relatively compact and so factor analysis should yield distinct and reliable factors (Field, 2005a). However, literature recommends that the KMO value should be greater than .50 if the sample size is adequate (Child, 1990; Field, 2005b). Subsequently, the KMO measure of this study achieved a high value of .71 suggesting the adequacy of the sample size for the factor analysis was met. The Bartlett's test of sphericity was also significant suggesting that the sample was not an identity matrix. The KMO and Bartlett's measure are used to measure sampling adequacy and non-identity matrix of the sample in the use of factor analysis (Field, 2005a, 2005b). The KMO and Bartlett's test of sphericity are presented in Table 1.

\subsection{Factor Analysis}

Factor analysis seeks to identify fundamental variables, or factors, that explain the pattern of correlations within a set of observed variables (Suhr, 2006). This analysis is often used in data reduction to identify a small number of factors that explain most of the variance that is observed in a much larger number of manifest variables. It is used to generate hypotheses regarding causal mechanisms or to screen variables for subsequent analysis (e.g. to identify collinearity, prior to performing a linear regression analysis).

The following steps were used for the factor analysis:

\subsubsection{Confirmatory Factor Analysis}

Confirmatory factor analysis (CFA) is a statistical technique used to verify the latent constructs in a set of observed variables. CFA allows the researcher to test the hypothesis that a relationship between observed variables and their underlying latent constructs exists (Suhr, 2006).

Cluster analysis. Cluster analysis encompasses a number of different algorithms and methods for grouping objects of similar kind into respective categories. A general question facing researchers in many areas of inquiry is how to organize 
observed data into meaningful structures, that is, to develop taxonomies. In other words cluster analysis is an exploratory data analysis tool which aims at sorting different objects into groups in a way that the degree of association between two objects is maximal if they belong to the same group and minimal otherwise. Given the above, cluster analysis is used to discover structures in data without providing an explanation or interpretation. In other words, cluster analysis simply discovers structures in data without explaining why they exist.

Scree plot it is a plot of the variance that is associated with each factor. A scree plot was used to illustrate the factors so identified. It can be seen that several factors were identified, but those that have eiginvalues of more than 1 were retained for the study (as show in figure 3).

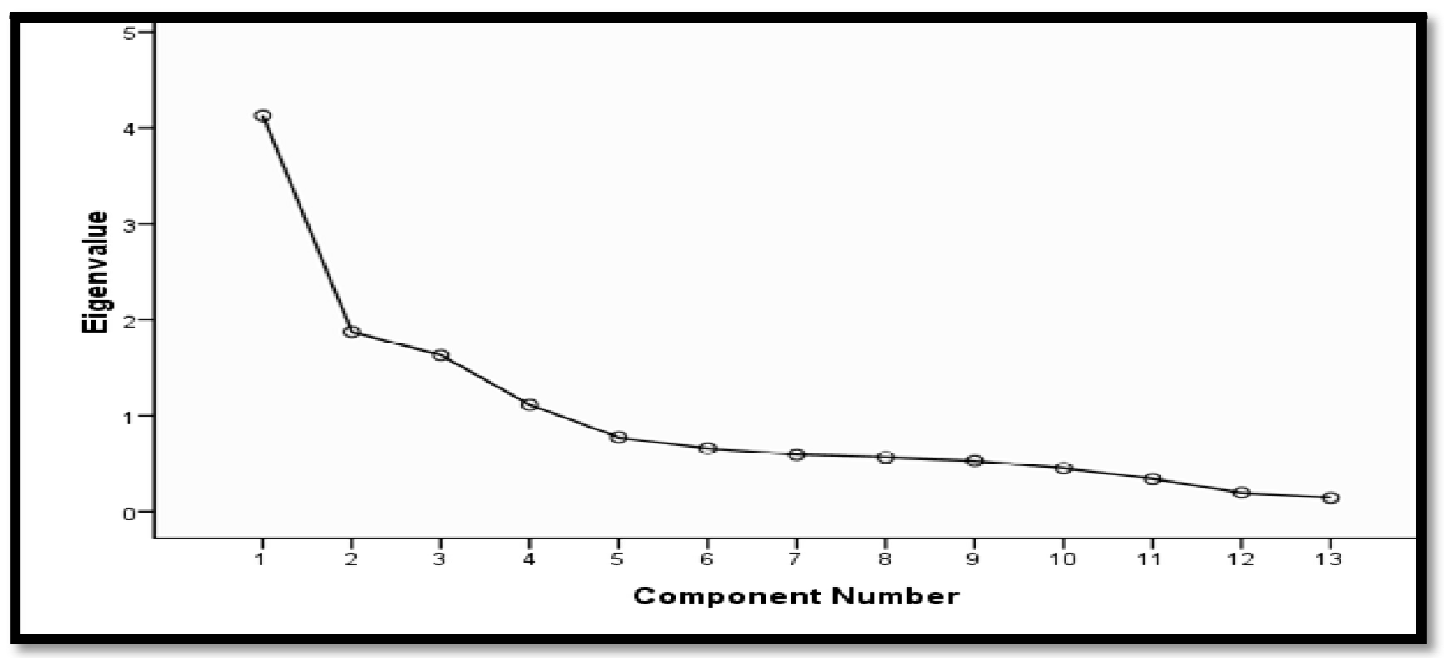

Figure 1: A Scree Plot Illustrating Factors Identified in the Study

Principal component analysis with varimax rotation was performed on the data. The factor analysis provided four factors with eigenvalues greater than one and collectively accounted for $67 \cdot 3 \%$ of variance as in Table 2 .

\begin{tabular}{|c|c|c|c|c|c|c|c|c|c|}
\hline \multirow[t]{2}{*}{ Component } & \multicolumn{3}{|c|}{ Initial Eigenvalues } & \multicolumn{3}{|c|}{$\begin{array}{c}\text { Extraction Sums of Squared } \\
\text { Loadings }\end{array}$} & \multicolumn{3}{|c|}{$\begin{array}{c}\text { Rotation Sums of Squared } \\
\text { Loadings }\end{array}$} \\
\hline & Total & $\begin{array}{c}\% \text { of } \\
\text { Variance }\end{array}$ & Cumulative \% & Total & $\begin{array}{c}\% \text { of } \\
\text { Variance }\end{array}$ & Cumulative \% & Total & $\begin{array}{c}\% \text { of } \\
\text { Variance }\end{array}$ & Cumulative \% \\
\hline 1 & 4.130 & 31.770 & 31.770 & 4.130 & 31.770 & 31.770 & 2.790 & 21.461 & 21.461 \\
\hline 2 & 1.873 & 14.410 & 46.179 & 1.873 & 14.410 & 46.179 & 2.170 & 16.692 & 38.153 \\
\hline 3 & 1.632 & 12.553 & 58.732 & 1.632 & 12.553 & 58.732 & 2.052 & 15.785 & 53.938 \\
\hline 4 & 1.113 & 8.562 & 67.294 & 1.113 & 8.562 & 67.294 & 1.736 & 13.357 & 67.294 \\
\hline 5 & .773 & 5.948 & 73.242 & & & & & & \\
\hline 6 & .659 & 5.067 & 78.309 & & & & & & \\
\hline 7 & .594 & 4.570 & 82.879 & & & & & & \\
\hline 8 & .565 & 4.348 & 87.227 & & & & & & \\
\hline 9 & .528 & 4.063 & 91.290 & & & & & & \\
\hline 10 & .454 & 3.490 & 94.780 & & & & & & \\
\hline 11 & .340 & 2.619 & 97.399 & & & & & & \\
\hline 12 & .195 & 1.497 & 98.896 & & & & & & \\
\hline 13 & .144 & 1.104 & 100.000 & & & & & & \\
\hline
\end{tabular}

Table 2: Total Variance Explained the Four Factors Extracted

Extraction Method: Principal Component Analysis

The components identified were respectively Perceived effort, Perceived competence, Usefulness, perceived interest.

The assumption for multiple-regression requires that, the residuals (predicted minus observed values) are distributed normally (i.e. follow the normal distribution). To check if the data is normally distributed a residual p-p plot with a line that depicts the distribution of residuals about the predicted values show even distribution. The closeness of the residuals to the predicted line (as shown in Figure 2) shows that the residuals are normally distributed, thereby fulfilling one of the necessary conditions for conducting linear regression. 


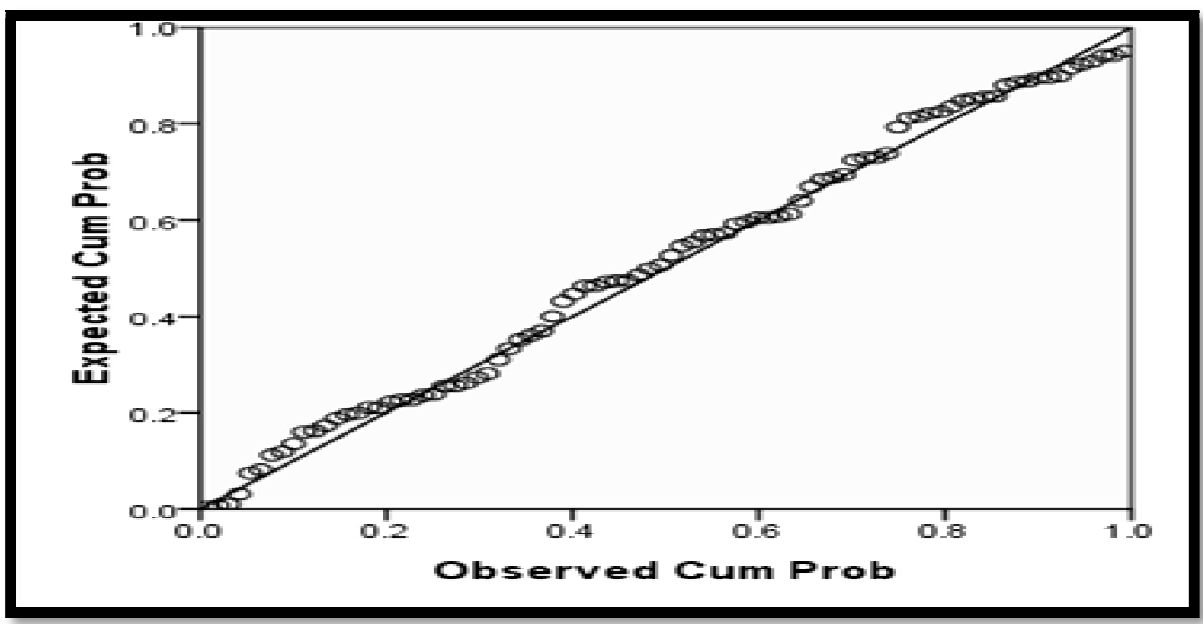

Figure 2: Scatter Plot of Residuals to Demonstrate Normality of Distribution

Another assumption is the Linearity test. A preferable method of detection is examination of residual plots as in Figure 3. The scatter plot of residuals indicates linear relationships, as they cluster around zero.

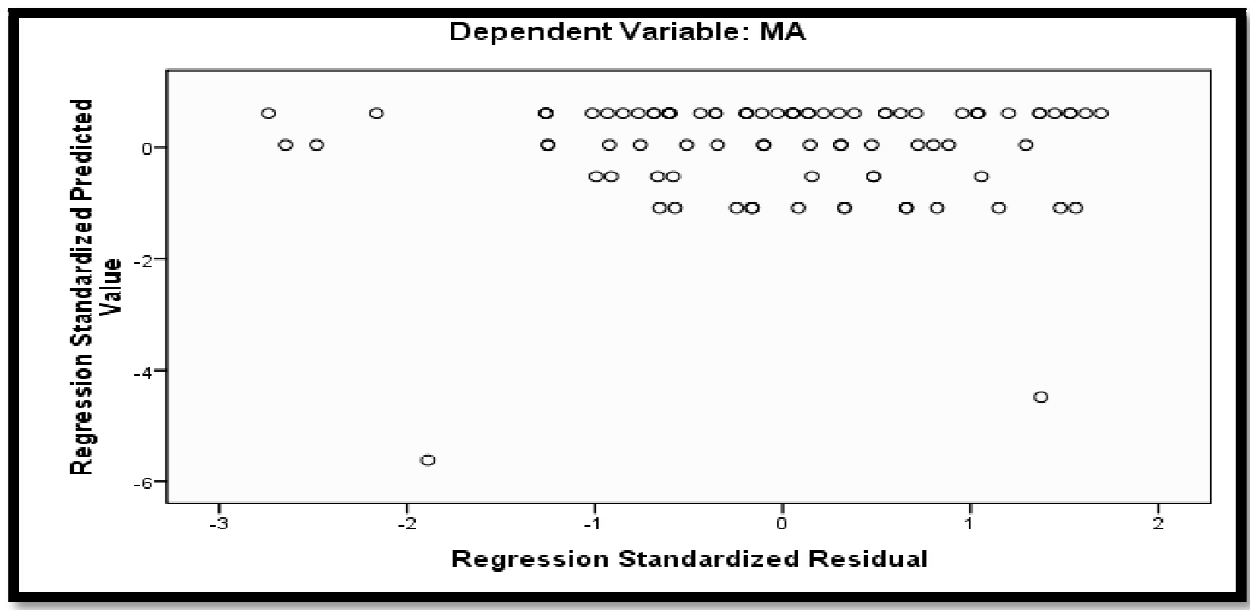

Figure 3: Linear Relationships with Standardized Residuals by Standardized Predicted Values

Homoscedasticity is another assumption to consider, which simply means that the variance of errors is the same across all variables. Ideally, the residuals are randomly scattered around 0 providing a relatively even distribution as shown in Figure 4

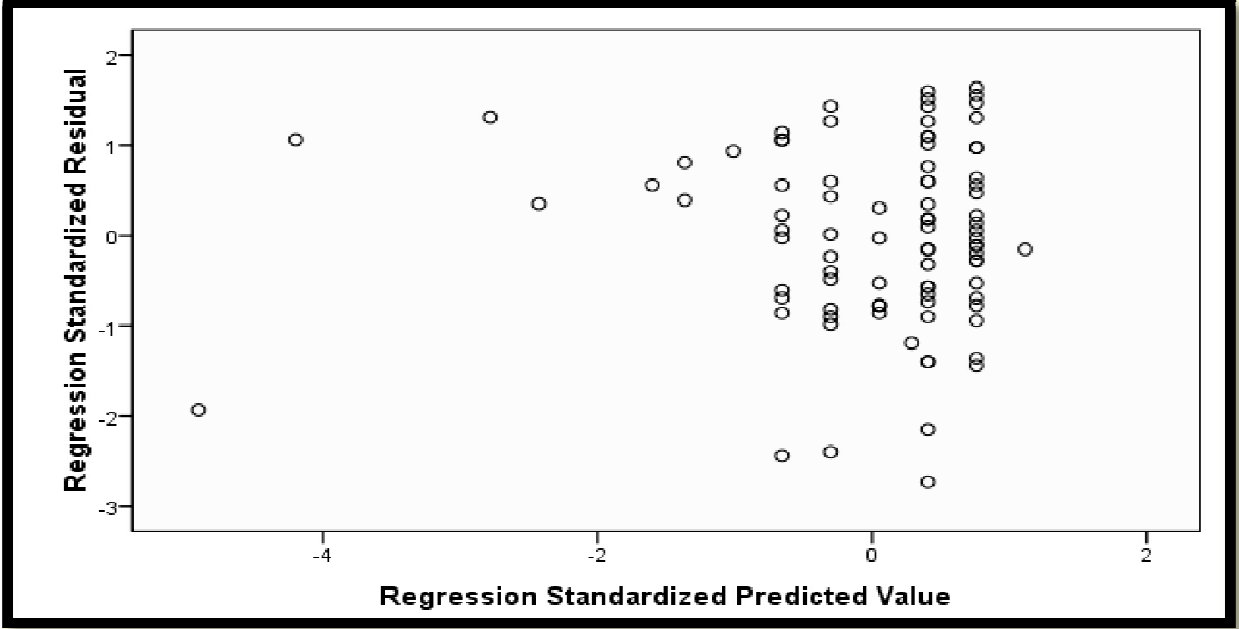

Figure 4: Residual Plots Depicting Test for Homoscedasticity 
Another assumption is that the residuals should be independent and measured by the Durbin-Watson test statistic, which tests for correlation errors as in Table 4.

\begin{tabular}{|c|c|c|c|c|c|}
\hline Model & R & R Square & Adjusted R Square & Std. Error of the Estimate & Durbin-Watson \\
\hline 1 & $.371^{\mathrm{a}}$ & .138 & .095 & 12.058 & \\
\hline 2 & $.370^{\mathrm{b}}$ & .137 & .105 & 11.990 & \\
\hline 3 & $.357^{\mathrm{c}}$ & .127 & .106 & 11.983 & \\
\hline 4 & $.335^{\mathrm{d}}$ & .112 & .102 & 12.012 & 1.934 \\
\hline
\end{tabular}

Table 3: Durbin-Watson Test Static for Correlation of Error

A. Predictors: (Constant), Perceived Effort, Perceived Competence, Usefulness, Perceived Interest

B. Predictors: (Constant), Perceived Effort, Usefulness, Perceived Interest

C. Predictors: (Constant), Perceived Effort, Perceived Interest

D. Predictors: (Constant), Perceived Interest

E. Dependent Variable: MA

Specifically it seeks to find out whether adjacent residuals are correlated. The test statistic could vary from 0 to 3 with a value 2 meaning the residual values are uncorrelated. In this research the Durbin-Watson test statistic was 1.939 which is approximately 2 , thereby fulfilling the last condition for conducting multiple regression analysis.

\section{Results and Discussion}

The research hypothesis was There is/ are no significant predictor(s) in the Multi-Dimensionality of Pre-Service Teachers' Intrinsic Motivation on Mathematics achievement'. This was design to find if there are significant predictors for Mathematics Achievement. To respond to the hypothesis, the backward stepwise regression method in multiple-regression was used, to explore whether perceived effort, competence, Usefulness, Perceived interest could be used to predict mathematics achievement.

\begin{tabular}{|c|c|c|c|c|c|}
\hline \multirow[t]{2}{*}{ Model } & \multicolumn{2}{|c|}{ Unstandardized Coefficients } & Standardized Coefficients & \multirow[t]{2}{*}{$\mathbf{T}$} & \multirow[t]{2}{*}{ Sg. } \\
\hline & B & Std. Error & Beta & & \\
\hline (Constant) & 27.560 & 11.389 & & 2.420 & .018 \\
\hline Usefulness & 2.581 & 2.842 & .120 & .908 & .367 \\
\hline perceived interest & 4.225 & 2.452 & .235 & 1.723 & .089 \\
\hline Perceived competence & .463 & 1.592 & .034 & .291 & .772 \\
\hline Perceived effort & 1.498 & 1.476 & .108 & 1.015 & .313 \\
\hline (Constant) & 27.839 & 11.285 & & 2.467 & .016 \\
\hline Usefulness & 2.666 & 2.811 & .124 & .949 & .346 \\
\hline perceived interest & 4.455 & 2.307 & .248 & 1.931 & .057 \\
\hline Perceived effort & 1.462 & 1.462 & .105 & 1.000 & .320 \\
\hline (Constant) & 33.403 & 9.635 & & 3.467 & .001 \\
\hline perceived interest & 5.754 & 1.856 & .320 & 3.101 & .003 \\
\hline Perceived effort & 1.710 & 1.438 & .123 & 1.189 & .238 \\
\hline (Constant) & 39.179 & 8.341 & & 4.697 & .000 \\
\hline perceived interest & 6.024 & 1.846 & .335 & 3.263 & .002 \\
\hline
\end{tabular}

Table 4: Backward Modeling of Prediction Equation for Selection of Best Model

a. Dependent Variable: AM

The results obtained in Table 4 show that only students' perceived interest, enters into the regression equation, yielding a coefficient of multiple correlation $(\mathrm{R})$ of .335 and $\mathrm{R}^{2}$ of .112 (meaning that only $11 \%$ of the total variance in mathematics achievement is explained by students' perceived interest. This result means that students' perceived interest is the only significant predictor of mathematics achievement in this work as shown by the prediction equation $(\mathrm{MA}=39.1790+$ 6.0244I). The coefficient 6.024 indicates the unit change in the mean score of mathematics achievement associated with a mean unit change in perceived interest score. Thus for every mean unit change in perceived interest score, mathematics achievement is predicted to be about 6 units higher. The finding here, goes contrary to Goldberg and Cornell (1998) revelation that intrinsic motivation (perceived interest) did not directly influence subsequent achievement.

This result probably implies that, the higher a student's perceived interest, the better her or his mathematics achievement. Thus, the final model (model 4) significantly improves our ability to predict mathematics achievement using perceived interest alone $(\beta=.34, p=.002)$. This is expected, because the backward stepwise regression begins to drop less or non-significant variables in the subsequent models. Perceived efforts, Perceived competence, Usefulness, Perceived interest were used in a standard regression analysis to predict mathematics achievement. The correlations of the variables are shown 
in Table 7. As can be seen, all correlations, except for the one between perceived usefulness and perceived effort, were statistically significant. The prediction model was statistically significant, $\mathrm{F}(1,84)=10.648, \mathrm{p}<.05$, and accounted for approximately $11.2 \%$ of the variance of self-esteem $\left(\mathrm{R}^{2}=.335\right.$, Adjusted $\left.\mathrm{R}^{2}=.102\right)$ as shown in Table 6 . The low variance accounting for mathematics achievement shows that other variables are equally likely to predict mathematic achievement, showing the need for further investigation. This study indicates that perceived competence, perceived usefulness and perceived effort are not significant predictors of mathematics achievement. The only variable that perhaps can influence mathematics achievement is perceived interest.

\begin{tabular}{|c|c|c|c|c|c|c|}
\hline \multicolumn{2}{|c|}{ Model } & Sum of Squares & Df & Mean Square & $\mathbf{F}$ & Sig. \\
\hline \multirow[t]{3}{*}{1} & Regression & 1881.149 & 4 & 470.287 & 3.235 & $.016^{\mathrm{a}}$ \\
\hline & Residual & 11776.414 & 81 & 145.388 & & \\
\hline & Total & 13657.564 & 85 & & & \\
\hline \multirow[t]{3}{*}{2} & Regression & 1868.849 & 3 & 622.950 & 4.333 & $.007^{b}$ \\
\hline & Residual & 11788.714 & 82 & 143.765 & & \\
\hline & Total & 13657.564 & 85 & & & \\
\hline \multirow[t]{3}{*}{3} & Regression & 1739.510 & 2 & 869.755 & 6.057 & $.004^{\mathrm{c}}$ \\
\hline & Residual & 11918.053 & 83 & 143.591 & & \\
\hline & Total & 13657.564 & 85 & & & \\
\hline \multirow[t]{3}{*}{4} & Regression & 1536.450 & 1 & 1536.450 & 10.648 & $.002^{\mathrm{d}}$ \\
\hline & Residual & 12121.114 & 84 & 144.299 & & \\
\hline & Total & 13657.564 & 85 & & & \\
\hline
\end{tabular}

Table 5: Prediction Models of Mathematics Achievement (MA) by Multi-Dimensionality of Intrinsic Motivation

a. Predictors: (Constant), Perceived Effort, Perceived Competence, Usefulness, Perceived Interest

b. Predictors: (Constant), Perceived Effort, Usefulness, Perceived Interest

c. C. Predictors: (Constant), Perceived Effort, Perceived Interest

d. D. Predictors: (Constant), Perceived Interest

e. E. Dependent Variable: AM

The results indicate that a student would only invest her time or his time in activities that are interesting and would depart from it when she or he finds it to be boring. This much revealing and require the attention of teachers. Tutors are required to teach mathematics in ways that always capture the interest of students, sustain this interest in ways that make mathematical concepts easier to understand. That means that students who demonstrate a lot of interest in the study of mathematics are more likely to succeed in it. Perhaps, they pay attention to the learning of mathematics, easily recall basic facts and concepts develop persistence mathematics related task, and exert a lot of effort in the study of mathematics. It is important to employ all means possible to develop students' interest in mathematics as it appears to be the driving force for students' mathematics achievement.

\section{Conclusion}

The research found that students' perceived interest as the only predictor of mathematics achievement. This study has important implications for educational practice. That means that students who demonstrate high levels of interest in the study of mathematics are more likely to succeed in it. It is important to employ all means possible to develop students' interest in mathematics as it appears to be the driven force for students' mathematics achievement and to conduct further investigations to identifying more predictors that could explain most variance in mathematics achievement.

\section{References}

i. Ahadzie, D.K. (2007). A model for predicting the performance of project managers in mass house building projects in Ghana. PhD thesis, University of Wolverhampton, UK.

ii. Alexander, P. A. (2006). Psychology in learning and instruction. Upper Saddle River, NJ: Pearson.

iii. Alexander, P. A., \& Murphy, P. K. (1998). The research base for APA's learner centred psychological principles. In N.M. Lambert, \& B.L. McCombs (Eds.), how students learn: Reforming schools through learner-centred education (pp. 2560). Washington D. C.: American Psychological Association.

iv. Ames, C. (1992). Classrooms: Goals, structures and student motivation. Journal of Educational Psychology, 84, 261271.

v. Areepattamannil, S., \& Freeman, J. G. (2008). Academic achievement, academic self-concept, and academic motivation of immigrant adolescents in the Greater Toronto Area Secondary Schools. Journal of Advanced Academics, 19(4), 700-743.Ary, D., Jacobs, L. C., \& Razavieh, A. (2002). Introduction to Research in Education (6th Ed.). Forth Worth: Harcourt Brace.

vi. Baadjies, L. (2008). Self-concept and academic achievement of Grade 9 pupils. Published M. Ed dissertation. Johannesburg: University of Johannesburg. Retrieved July 2011, from http:/ / hdl.handle.net/ 10210/ 1407 
vii. Berndt, T.J., \& Miller, K. E. (1990). Expectancies, values, and achievement in junior high school. Journal of Educational Psychology, 82, 319-326.

viii. Bomia, L., Beluzo, L., Demeester, D., Elander, K., Johnson, M., \& Sheldon, B. (1997). The impact of teaching strategies on intrinsic motivation. Champaign, IL: ERIC Clearinghouse on Elementary and Early Childhood Education. (ERIC Document Reproduction Service No. ED 418 925).

ix. Child, D. (1990). The Essentials of Factor Analysis, (2nd ed.). Cassel Educational Ltd, London.

x. Clark, M. H., \& Schroth, C.A. (2010). Examining relationships between academic motivation and personality among college students. Learning and Individual Differences, 20, 1924.

xi. Cohen, L., and Manion, L., \& Morrison, K., (2000). Research Methods in Education (5th Edition). London: Routledge Falmer.

xii. Dambudzo, I. I. (2009). The relationship between learner self-concept and achievement in secondary schools in Zimbabwe. Unpublished DEdthesis. Retrieved July 2011, from http:/ / hdl.handle.net/ 10500/ 2393

xiii. Deci, E. L., \& Ryan, R. M. (1985). Intrinsic motivation and self determination theory of human behavior. New York: Plenum.

xiv. Deci, E. L., \& Ryan, R. M. (1991). A motivational approach to self: Integration in personality. In R. Dienstbier (Ed.), Nebraska symposium on motivation: Perspectives on motivation (pp. 237- 288). Lincoln: University of Nebraska Press.

xv. Deci, E. L., \& Ryan, R. M. (2000). The "what" and "why" of goal pursuits: Human needs and the self-determination of behaviour. Psychological Inquiry, 11, 227-268.

xvi. DiPerna, J. \& Elliot, S., (1999). Development and validation of the Academic Competence Evaluation Scales. Journal of Psychoeducational Assessment, 17, 207-225.

xvii. Dweck, C. S., \& Leggett E. L. (1988). A social-cognitive approach to motivation and personality. Psychological Review, 95, 256-273.

xviii. Eccles, J. S., Wigfield, A., \& Schiefele, U. (1998). Motivation to succeed. In W. Damon \& N. Eisenberg (Eds.), Handbook of child psychology, (pp. 1017-1095). New York: Wiley.

xix. Field, A. (2005a). Discovering Statistics Using SPSS for Windows, London: Sage Publications.

xx. Field, A. (2005b). Factor Analysis Using SPSS: Theory of SPSS: Theory and Application. Retrieved February 2011, from http:/ / www.sussex.ac.uk/ users/ andyf/ factors/ pdf

xxi. Gottfried, A. E. (1990). Academic intrinsic motivation in young elementary school children. Journal of Educational Psychology, 82, 525-538.

xxii. Goldberg, M. D. \& Cornell, D. G. (1998). The influence of intrinsic motivation and self-concept on academic achievement in second- and third-grade students. Journal for the education of the Gifted, 21(2), 179-205.

xxiii. Gorsuch, R. L. (1983). Factor Analysis, Hillsdale, NJ: Lawrence Erlbaum.

xxiv. Gredler, M. E. (2001). Learning and instruction: Theory into practice. (4th ed.). Prentice- Hall, I nc., Upper Saddle River, New Jersey.

xxv. McAuley, E., Duncan, T., \& Tammen, V. V. (1987). Psychometric properties of the Intrinsic Motivation Inventory in a competitive sport setting: A confirmatory factor analysis. Research Quarterly for Exercise and Sport, 60, 48-58.

xxvi. McMillan, J. H., \& Schumacher, S. (2006). Research in education: Evidence-based inquiry (6th ed.). Boston: Pearson.

xxvii. Meece, J. L., \& Holt, K. (1993). A pattern analysis of students' achievement goals. Journal of Educational Psychology, 85, 582- 590 .

xxviii. Middleton, J. A, \& Spanias, P. A. (1999). Motivation for Mathematics achievement: Findings, Generalizations, and Criticisms of the Research. Journal for Research in Mathematics Education, 30(1), 65-88.

xxix. Mwamwenda, T. S. (1995). Educational Psychology: an African perspective. Durban: Butterworth.

xxx. Nolen, S. B., \& Nicholls, J. G. (1993). Elementary school pupils' views on the effectiveness of motivational strategies in mathematics. British Journal of Educational Psychology, 63, 416-431.

xxxi. Nolen, S. B., \& Nicholls, J. G. (1993). Elementary school pupils' views on the effectiveness of motivational strategies in mathematics. British Journal of Educational Psychology, 63, 416-431

xxxii. Nunnally, J. C. (1978). Psychometric theory. New York: McGraw-Hill.

xxxiii. Owusu, M. D. and Badu, E. (2009). "Determinants of contractors' investment finance strategy in Ghana: Conceptual and empirical explanations. Journal of Financial Management of Property and Construction, 14(1), 21-33.

xxxiv. $\quad$ Pintrich, P. R., Marx, R. W., \& Boyle, R. A. (1993). Beyond cold conceptual change: The role of motivational beliefs and classroom contextual factors in the process of conceptual change. Review of Educational Research, 63, 167-199.

xxxv. Pintrich, P. R. \& Schunk, D. H. (1996). Motivation in education: Theory, research, and applications. Englewood Cliffs: Prentice Hall.

xxxvi. Ryan, R. M, \& Deci, E. L. (2000). Intrinsic and extrinsic motivations: Classic definitions and new directions. Contemporary Educational Psychology, 25, 54-67.

xxxvii. Schick, H., \& Phillipson, S. N. (2009). Learning motivation and performance excellence in adolescents with high intellectual potential: what really matters? High Ability Studies, 20(1), 15-37. 
xxxviii. Schoenfeld, A. H. (1992). Learning to think mathematically: Problem solving, meta-cognition, and self-making in mathematics. In D. Grouws, (ed.), Handbook for research on Mathematics teaching and learning. N. Y.: MacMillan.

xxxix. Skinner, E. \& Belmont, M. (1991). A longitudinal study of motivation in school: Reciprocal effects of teacher behaviour and student engagement. Unpublished manuscript, University of Rochester, Rochester, NY.

xl. Spinath, B., \& Steinmayr, R. (2007). Intrinsic motivation and competence beliefs. Retrieved, July 2011 from http:/ / www.srcd.org/ journals/ cdev / 0-0/ spinath.pdf

xli. Stipek, D. (1998). Motivation to learn: From theory to practice. Boston: Allyn and Bacon.

xlii. Suhr, D. D. (2006). Exploratory or confirmatory factor analysis? Proceedings of the Thirty-first Annual SAS Conference (SUGI 31), Paper 200-3.

xliii. Wylie, R. C. (1989). Measures of the self-concept. Lincoln: University of Nebraska Press.

xliv. Zimmerman, B. J., Bandura, A., \& Martinez-Pons, M. (1992). Self-motivation for academic attainment: The role of selfefficacy beliefs and personal goal-setting. American Educational Research Journal, 29, 663-676. 